Faculdade

de Ciências Econômicas UFRGS

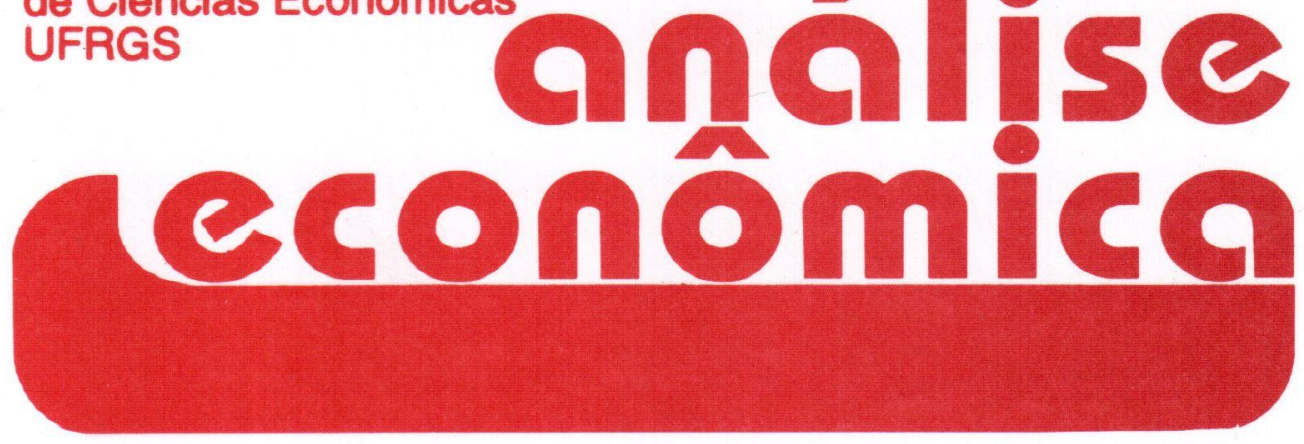

- Finance and Growth:

is Schumpeter Right?

- Philip Arestis

- Panicos Demetriades

- Repensando a

Revolução Marginalista

- Ricardo Luis C. Feijó

- O Papel dos

Rendimentos Crescentes

na Localização Econômica

- Paulo Augusto P. de Britto

- Credibilidade e Mercado Secundário da Dívida Externa Brasileira

- Paulo Calderon

- Rosa Fontes

- Fronteira de Eficiência sob Condições de Risco

- Luís A. de Araújo

- José Vicente Caixeta Filho

- A Criação de

Municípios e seu Impacto na

Qualificação do Espaço Urbano

- Maria Conceição B. Scussel

- Um Estudo Crítico das Relações entre as Poupanças Privada,

Pública e Nacional

- Martin R. Cavalcanti

- Joanílio R. Teixeira
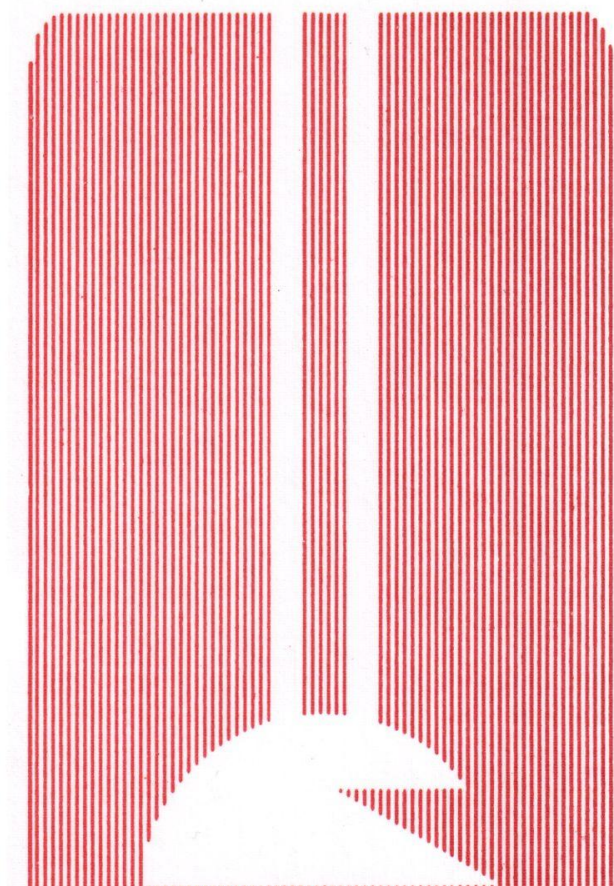

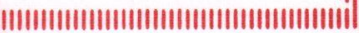

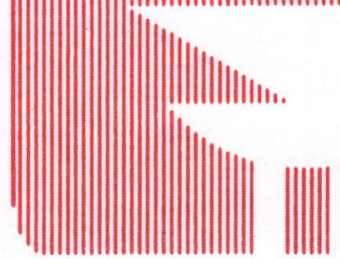

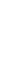


UNIVERSIDADE FEDERAL DO RIO GRANDE DO SUL

Reitora: Prof ${ }^{\mathrm{a}}$. Wrana Maria Panizzi

FACULDADE DE CIÊNCIAS ECONÔMICAS

Diretora: Prof ${ }^{\mathrm{a}}$. Otilia Beatriz Kroeff Carrion

CENTRO DE ESTUDOS E PESQUISAS ECONÔMICAS

Diretor. Prof. Fernando Ferrari Filho

DEPARTAMENTO DE CIÊNCIAS ECONÔMICAS

Chefe: Prof. Luiz Alberto Oliveira Ribeiro de Miranda

CURSO DE PÓS-GRADUAÇÃO EM ECONOMIA

Coordenador. Prof. Marcelo Savino Portugal

CURSO DE PÓS-GRADUAÇÃO EM ECONOMIA RURAL

Coordenador. Prof. Carlos Guilherme A. Mielitz Netto

CONSELHO EDITORIAL: Achyles B. Costa, Aray M. Feldens, Carlos A. Crusius, Carlos G. A. Mielitz Netto, Eduardo A. Maldonado Filho, Eduardo P. Ribeiro, Eugênio Lagemann, Fernando Ferrari Filho, Gentil Corazza, Marcelo S. Portugal, Nali J. Souza, Otília B. K. Carrion, Paulo A. Spohr, Paulo D. Waquil, Pedro C. D. Fonseca, Roberto C. Moraes, Ronald Otto Hillbrecht, Stefano Florissi, Eleutério F. S. Prado (USP), Fernando H. Barbosa (FGV/RJ), Gustavo Franco (PUC/RJ), João R. Sanson (UFSC), Joaquim P. Andrade (UnB), Juan H. Moldau (USP), Paul Davidson (Univ. of Tennessee), Werner Baer (Univ. of Illinois).

COMISSÃO EDITORIAL: Fernando Ferrari Filho, Gentil Corazza, Paulo Dabdab Waquil, Marcelo Savino Portugal, Roberto Camps Moraes.

EDITOR: Eduardo Augusto Maldonado Filho

EDITOR ADJUNTO: Gentil Corazza

SECRETARIA: Revisão de textos: Vanete Ricacheski.

FUNDADOR: Prof. Antônio Carlos Santos Rosa

Os materiais publicados na revista Análise Econômica são da exclusiva responsabilidade dos autores. É permitida a reprodução total ou parcial dos trabalhos, desde que seja citada a fonte. Aceita-se permuta com revistas congêneres. Aceitam-se, também, livros para divulgação, elaboração de resenhas e recensões. Toda correspondência, material para publicação (vide normas na terceira capa), assinaturas e permutas devem ser dirigidos ao seguinte destinatário:

PROF. EDUARDO AUGUSTO MALDONADO FILHO

Revista Análise Econômica - Av. João Pessoa, 52 CEP 90040-000 PORTO ALEGRE - RS, BRASIL

Telefones: (051) 316-3324 e 316-3440 - Fax: (051) 316-3990 rae@vortex.ufrgs.br 


\title{
UM ESTUDO CRÍTICO DAS RELAÇÕES ENTRE AS POUPANÇAS PRIVADA, PÚBLICA E NACIONAL*
}

\author{
Martim Ramos Cavalcanti * \\ Joanilio Rodolpho Teixeira
}

\begin{abstract}
RESUMO
Com a dificuldade de crescimento enfrentada pela economia brasileira após a implementação do Plano Real, tem-se discutido a necessidade de diminuição do déficit público como estratégia para promover o crescimento. O argumento utilizado é que, diminuindo-se o déficit público, aumenta-se a poupança governamental e, desta forma, a poupança doméstica, que seria fundamental para o investimento. As conclusões de Corbo \& Schimidt-Hebbel (1991), obtidas através de uma análise econométrica clássica, reforçam este argumento. $O$ presente trabalho, utilizando-se, não apenas, de uma amostra maior do que a dos autores e da nova econometria, critica tais conclusões para o Brasil.
\end{abstract}

Cód AEA: 212

Palavras-Chave: poupança privada, poupança pública, poupança nacional, cointegração

\section{ABSTRACT}

With the difficulty in growing faced by the Brazilian economy after the implementation of Plano Real, the necessity of diminishing the public deficit has been discussed as a strategy to promote growth. The argument is that diminishing the public expenditure there will be an increase in the public saving, which would be fundamental to investment. The conclusions of Corbo \& Schimidt-Hebbel (1991)'s work, which were obtained by a classical econometric analysis, give support to this argument. The present work, making use of both a larger sample than the mentioned autors and The New Econometrics, criticize those conclusions for Brazil.

AEA Code: 212

Key Words: private savings, public saving, national savings and cointegration.

"Bolsista do programa PET-ECO

"Professor Titular do Departamento de Economia - UNB

Os autores agradecem a colaboração da Professora Dra Adriana Amado, Ana Carolina

Viana e Fabiano R. Bastos e aos referees. Registramos o apoio do CNPq para o

desenvolvimento da pesquisa. Como de praxe, o conteúdo do trabalho é de inteira responsabilidade dos autores.

\begin{tabular}{|l|l|l|l|l|}
\hline ANÁLISE ECONÔMICA & ANO 16 & N.30 & SETEMBRO/98 & p.133-146 \\
\hline
\end{tabular}




\section{1 - INTRODUÇÃO}

O sucesso do Plano Real em conter a inflação possibilitou que outros problemas macroeconômicos, antes relegados a segundo plano, passassem a ser discutidos. Um tema central tem sido o crescimento econômico sustentável, com a manutenção da estabilidade já conseguida.

Como os principais instrumentos de política econômica vêm sendo usados na tarefa de manter o Plano, o governo tem destacado a importância de realizar reformas no modus operandi (reforma da previdência, estabilidade do funcionalismo público, reforma fiscal e outras) do Estado, para viabilizar o crescimento do país.

O argumento a favor de tais reformas é que proporcionariam um aumento da poupança governamental. E partindo da hipótese de que existe uma correlação positiva entre poupança governamental e nacional e que essa poupança se transforma em investimento, conclui-se que as reformas defendidas e executadas pelo governo teriam o efeito de fomentar o crescimento econômico do País. A validade desta relação justificaria a preocupação e a urgência em aprovar tais reformas, pois em um momento em que o capital externo tem se mostrado extremamente volátil e instabilizador, com as recentes crises asiáticas, a substituição deste pelo capital interno geraria uma maior segurança para o país.

Este paper coloca em dúvida, para o caso brasileiro, o argumento empírico de que um aumento da poupança governamental eleva a poupança nacional. Outra crítica que pode ser feita é teórica, alegando-se que não é necessariamente verdade que toda poupança se torne investimento. A igualdade entre poupança e investimento é um pressuposto da teoria neoclássica. Em outras teorias, como a keynesiana, o investimento precede a poupança e a determina. Entretanto o presente trabalho não tem por objetivo discutir questões teóricas, e sim aplicadas. Como base para a crítica será usado o trabalho de Corbo e Schmidt-Hebbel (1991), os quais passaremos a chamar de $\mathrm{CSH}$, que valida a existência de uma relação positiva entre poupança nacional e poupança governamental.

$\mathrm{Na}$ seção dois serão apresentados o modelo e as conclusões tiradas por CSH. A terceira aborda uma questão metodológica, as diferenças entre a nova econometria e a econometria clássica, destacando as fraquezas da segunda como teste empírico para qualquer teoria. A quarta seção traz o modelo adotado e os resultados empíricos do estudo. Finalmente, temos a conclusão do trabalho. 


\section{2 - POUPANÇA GOVERNAMENTAL E NACIONAL, RESULTADOS DE CORBO E SCHMIDT-HEBBEL}

Eles, $\mathrm{CSH}$, estudam a possibilidade de políticas públicas, em paises em desenvolvimento, aumentarem o nivel de poupança nacional. A amostra utilizada engloba 13 países: Argentina, Brasil, Chile, Colômbia, Costa Rica, México, Peru, Venezuela, Gana, Paquistão, Filipinas, Tailândia e Zimbabue. . O resultado encontrado é que um aumento na poupança governamental não é compensado por uma redução, na mesma proporção, da poupança privada, funcionando, portanto, como um meio de aumentar a poupança nacional.

A equação usada para analisar a relação entre a poupança privada e a governamental, após uma série de manipulações algébricas e estimações econométricas é:

$$
\frac{C_{p_{t}}}{D Y_{P_{t}}}=\beta_{0}+\beta_{1} \frac{P D Y_{t}}{D Y_{P_{t}}}+\beta_{2} \frac{P S_{G_{t}}}{D Y_{P_{t}}}+\beta_{3} r_{t}+\beta_{4} I N F_{1}+\beta_{5} \frac{M_{t}}{D Y_{P_{t}}}+\beta_{6} \frac{F S_{t}}{D Y_{P_{T}}}+\varepsilon
$$

onde $\mathrm{C}_{\mathrm{pt}}$ é o consumo privado, DY é a renda privada corrente disponível, $P D Y_{t}$ é a renda privada permanente disponivel, $\mathrm{PS}_{\mathrm{G}}$ é a poupança pública permanente, $r$ é a taxa de juros real, INF é a taxa de inflação doméstica, $M$ seria $\mathrm{M}_{4}$, FS é a poupança externa e $\varepsilon$ representa o termo erro estocástico.

Utilizando uma estimação em pooled para os países estudados, o resultado encontrado é que, para cada aumento de uma unidade monetária da poupança governamental, o consumo privado aumenta (ou a poupança privada diminui) de $\$ 0,44$ a $\$ 0,49^{2}$.

Para analisar a influência da poupança governamental sobre a poupança privada e a nacional, a equação (1) foi reescrita levando-se em conta os resultados econométricos precedentes e considerando-se a renda como a soma do consurno e da poupança. Deste modo, sendo (1 - cons) a propensão a poupar, obteve-se para a poupança privada $\left(S_{p}\right)$ :

$$
S_{p}=(1 \text { - cons }) D Y_{p} \cdot 0,24 P D Y_{t}-0,5 P S_{g}-0,39 F S
$$

Após manipulações matemáticas, os autores verificam que, para cada aumento de uma unidade na poupança pública, em função de uma diminuição dos gastos públicos, há uma redução entre 16 e 50 centavos ñ. poupança privada. Caso o aumento da poupança governamental seja obtido

\footnotetext{
${ }^{1}$ Provavelmente em decorrrência de possuir apenas oito observaçōes de cada país, os autores foram obrigados a usar um grande número de países para aumentar a variância da amostra.

${ }^{2} \mathrm{CSH}$ encontraram que a inflação, a taxa de juros e M4 não foram significantes para a amostra estudada - Tabela 4.
} 
via aumento da tributação, a redução da poupança privada será de 48 a 65 centavos.

Assim, eles concluem que um aumento na poupança governamental implica um aumento da poupança nacional, dada a complementaridade entre a primeira e a última. Ainda, segundo os mesmos, o melhor caminho de se atingir tal meta é a redução dos gastos públicos.

\section{3 - A NOVA ECONOMETRIA E A ECONOMETRIA CLÁSSICA}

Dentro do que se convencionou chamar de nova econometria, surgem preocupações com relação à estacionariedade das séries, a validade da relação de longo prazo entre as variáveis e os mecanismos de ajuste para avaliar o comportamento de curto prazo. As séries temporais passaram a ser analisadas como geradas por um processo estocástico e o conjunto de dados, a amostra estudada, como a realização de um processo estocástico (Gujarati, 1995).

Um dos pontos de partida para esta nova abordagem foi a possibilidade da existência de relações non sense entre certas variáveis, mesmo quando a regressão apresentava um elevado $R$ quadrado, estatísticas $F$ e $t$ altas e indicando a significância de todos os parâmetros. Vários autores já haviam sugerido a possibilidade de se ter uma relação espúria entre variáveis, quando se utilizava a metodologia da econometria clássica, um texto seminal é o de Granger e Newbold (1974).

$\mathrm{CSH}$ usam o instrumental clássico de análise econométrica sem se preocupar com a estacionariedade das séries e as conseqüências de tal para a validade do estudo. Além disso, e um problema bem maior, os autores, provavelmente em virtude da pequena amostra disponível para cada país ( oito anos), agregaram vários países (Brasil, México, Argentina, Chile, Costa Rica, Tailândia, Filipinas, Zimbabue, Paquistão, entre outros) com características diferentes, para aumentar a variância. Com base nestes dados, eles rodam a regressão e chegam a uma conclusão que é extrapolada como válida, para cada país tomado separadamente ${ }^{3}$. Deste modo, tanto para o Paquistão quanto para o Brasil é tida como verdadeira a relação postulada pelos autores de que um aumento da poupança novernamental gera um aumento da poupança nacional, dado que para

\footnotetext{
${ }^{3}$ Este é um outro ponto que pode ser criticado na metodologia adotada. Os autores não utilizam os métodos adequados para estimação de dados na forma "painel". Não se utilizam do método de "efeitos fixos" (com isso obrigam os diferentes países a ter o mesmo intercepto), tão pouco do método de "componentes de erro", o mais indicado uma vez que a partir de uma amostra os autores fazem inferências sobre a população (Judge et alli, 1988) (Greene, 1997).
} 
cada aumento de uma unidade da poupança do governo a redução da poupança privada é menor que a unidade.

Bastos e Gomes (1996) classificam o trabalho realizado por CSH como "garimpagem econométrica", haja vista que os autores já têm um resultado a priori e apenas usam de um instrumental para "torturar" os dados até que estes corroborem a hipótese previamente levantada.

Com relação ao estudo específico, para o caso brasileiro, deve-se mencionar os artigos de Bastos e Gomes (1996) e de Bastos e Teixeira (1997). O último utiliza uma abordagem com base nos instrumentais da nova econometria, porém a amostra é reduzida, quinze anos (1980 a 1995), e a cointegração é tentada somente entre consumo privado e déficit público (proxi para a poupança governamental).

O problema da amostra reduzida está em não englobar um período de tempo suficiente para captar o comportamento de longo prazo das variáveis, de modo que, se a amostra não capta o comportamento de longo prazo das variáveis, é de certa forma, de se esperar que elas não cointegrem. Além disso, eles deixaram de lado o PIB, a poupança externa, a taxa de juros e o M4. Se as variáveis deixadas de fora do modelo fizerem parte do processo gerador de dados, a análise fica prejudicada.

No presente trabalho aumentou-se a amostra estudada. Agora o periodo englobado vai de 1970 a 1995, as demais variáveis são estudadas e a proxy utilizada para a poupança do governo foi o consumo do governo.

\section{4 - O MODELO E RESULTADOS}

O modelo analisado foi:

$$
C_{p r i v(t)}=\beta_{0}+\beta_{1} C_{p u b(t)}+\beta_{2} Y_{(t)}+\beta_{3} i_{(t)}+\beta_{4} M 4_{(t)}+\beta_{5} P E_{(t)}+\varepsilon_{(t)}
$$

As variáveis usadas são: consumo privado (proxy para poupança privada) como regressando, consumo público (proxy para poupança do governo), PIB, taxa de juros (bank rate), M4 e poupança externa ${ }^{4}$ como regressores.

O primeiro passo será a realização de testes para verificar a estacionariedade ou não das variáveis. Para isso, foram adotados testes visuais e estatísticos. Dentre os visuais destacam-se a análise dos valores da série ao longo do tempo e o estudo do correlograma.

O Gráfico 1 traz os valores das séries deflacionadas ao longo do tempo. As variáveis PIB, M4, consumo privado e público, mostram-se nitidamente como não estacionárias (com mudança de média). Com respeito às

\footnotetext{
${ }^{4}$ As variáveis consumo privado, consumo do governo, M4 e taxa de juros (bank rate) foram retiradas do International Financial Statistics, o PIB e a poupança externa foram retiradas da revista Conjuntura Econômica.
} 
variáveis poupança externa e taxa de juros restam dúvidas, principalmente com relação à última.
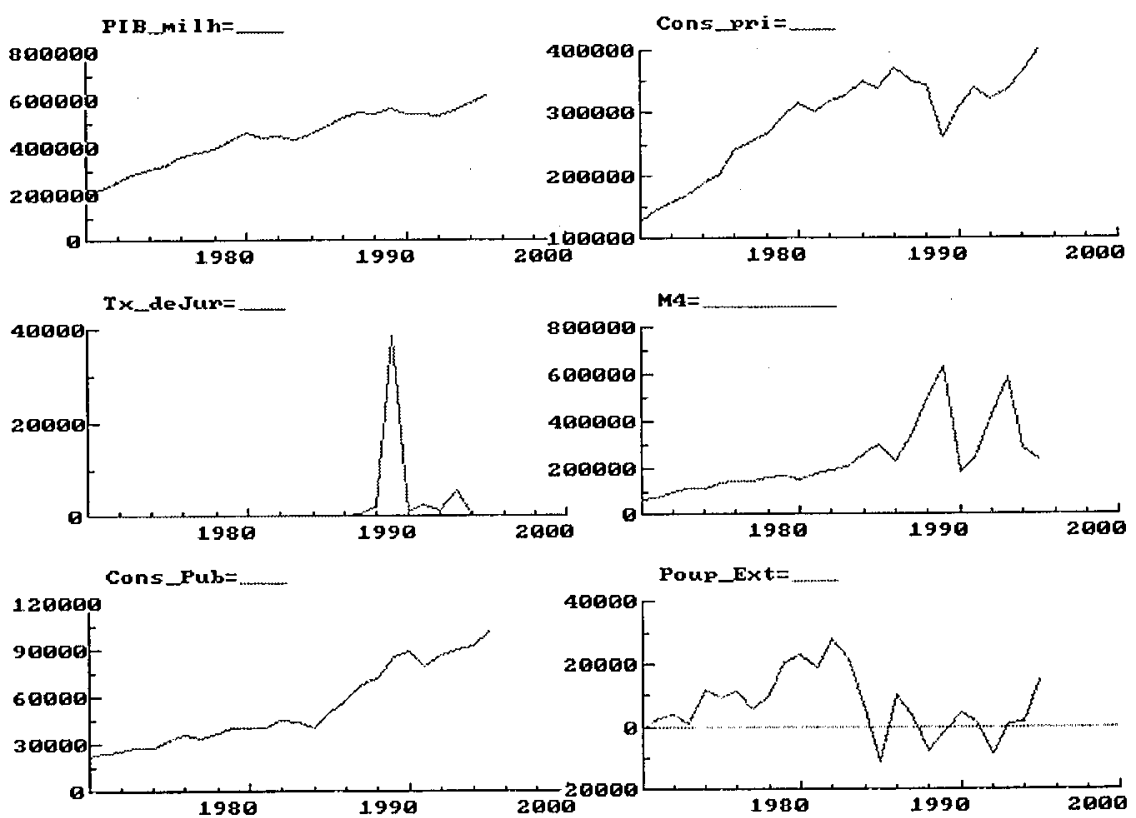

Gráfico 1 - Séries ao Longo do Tempo

O segundo passo é observar o correlograma ${ }^{5}$ das séries. Quando a série é estacionária, a correlação entre os valores da mesma decai rapidamente, o que seria o caso da taxa de juros, onde os "palitos" são todos pequenos. Quando a série é não estacionária, os valores do passado têm grande influência sobre o valor presente, a série tem uma "memória". Este caso seria observado para as demais variáveis.

A análise do gráfico dos valores da taxa de juros e do correlograma já seriam fortes indícios da estacionariedade desta, mas adicionou-se o teste Dickey-Fuller ${ }^{6}$. No entanto os resultados do mesmo deve ser considerado com cuidado, pois já é um fato estilizado que ele freqüentememte comete o

${ }^{5}$ O correlograma é dado pela relação entre a covariância de lag k e a variância.

${ }^{6}$ A versão utilizada foi a aumentada do teste (Augmented Dickey-Fuller), para o caso de autocorrelação serial dos resíduos. O teste fica assim (sem a presença de tendência):

$\Delta Y_{t}=\beta_{0}+\delta Y_{t-1}+\alpha_{i} \sum_{i=1}^{m} \Delta Y_{t-i}+\mathcal{E}_{t}$ 
erro tipo II, especialmente na presença de quebras estruturais (outliers). Fato observado no gráfico da taxa de juros.

Os resultados do teste Dickey-Fuller, aumentado com constante para as variáveis estudadas, estão na Tabela 1. Com base na mesma, conclui-se pela estacionariedade da série taxa de juros $\left(l_{0}\right)$ - mesmo com a presença de quebras, quando o teste aplicado tende a rejeitar a estacionariedade, verificou-se o contrário - não estacionariedade das demais variáveis.

Tabela 1 - Teste ADF com as Variáveis em Nível

\begin{tabular}{c|r|r}
\hline Variável & t-adf & lag \\
\hline PIB & $-1,5952$ & 0 \\
PIB & $-1,3334$ & 1 \\
Consumo privado & $-1,6248$ & 0 \\
Consumo privado & $-1,6034$ & 1 \\
Taxa de Juros & $-4,5131^{\star *}$ & 0 \\
Taxa de Juros & $-3,1250^{*}$ & 1 \\
M4 & $-2,5463$ & 0 \\
M4 & $-2,4797$ & 1 \\
Consumo público & 0,65125 & 0 \\
Consumo público & 0,60363 & 1 \\
Poupança externa & $-2,3769$ & 0 \\
Poupança externa & $-2,1897$ & 1 \\
\hline
\end{tabular}

Os valores críticos são: $5 \%=-2,997,1 \%=-3,75$

Para as variáveis PIB, consumo público e privado, também foi feito o mesmo teste, incluindo uma tendência em virtude do comportamento gráfico apresentado. No entanto, o teste corroborou o resultado já encontrado, ou seja a não estacionariedade.

Mesmo assim, para evitar qualquer dúvida, procedeu-se ao teste de cointegração de Phillips-Perron, que considera a possibilidade de existência de quebras estruturais na série e as modela para evitar algum viés. Os resultados encontrados podem ser vistos na Tabela 2 e corroboram os resultados encontrados no teste ADF. 
Tabela 2 - PHILLIPS-PERRON TESTS - TRUNCATION LAG $=1$

VARIÁVEL : Consumo Público

NULL HYPOTHESIS TEST STATISTIC

ASY. CRITICAL VALUE 10\%

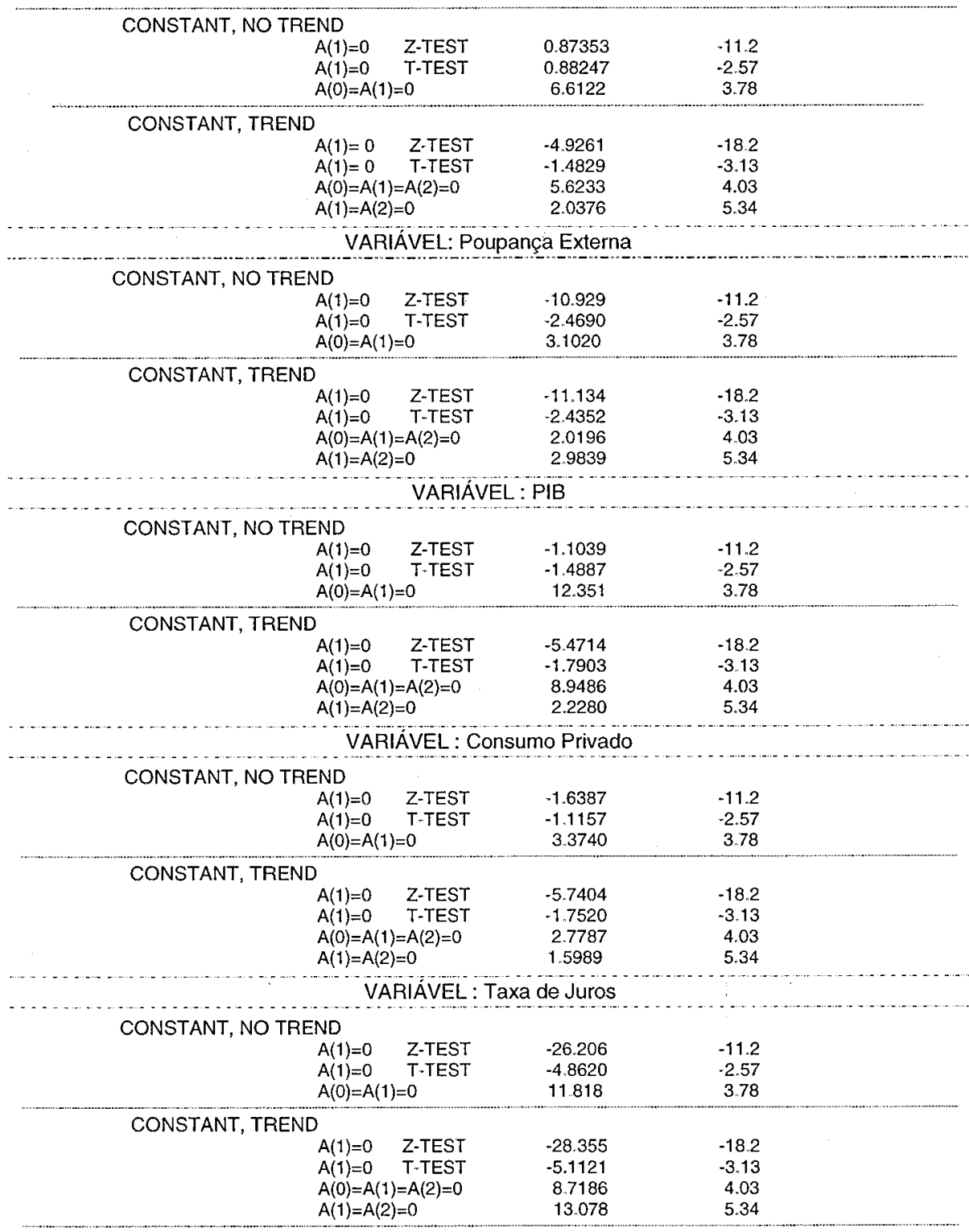


O passo seguinte consiste em calcular a diferença das séries para descobrir a ordem de integração delas. Após a primeira diferença, as variáveis se tornaram estacionárias, conforme pode ser visto na Tabela 3. Deste modo, as variáveis são ditas integradas de ordem um, $I_{1}$.

\begin{tabular}{c|r|r} 
Tabela $3-$ Teste ADF para as Variáveis após a Primeira Diferença \\
\hline Variável & \multicolumn{1}{|c}{ t-adf } & lag \\
\hline DPIB & $-3,5305^{\star}$ & 0 \\
DPIB & $-2,4562$ & 1 \\
DConsumo privado & $-5,3214^{\star *}$ & 0 \\
DConsumo privado & $-3,2933^{\star}$ & 1 \\
DM4 & $-5,1384^{\star *}$ & 0 \\
DM4 & $-6,0276^{\star *}$ & 1 \\
DConsumo público & $-4,2435^{\star *}$ & 0 \\
DConsumo público & $-3,4616^{*}$ & 1 \\
DPoupança externa & $-5,2042^{* *}$ & 0 \\
DPoupança externa & $-4,5962^{* *}$ & 1 \\
\hline
\end{tabular}

Os valores críticos são: $5 \%=-2,997,1 \%=-3,75$

Novamente procedeu-se ao teste de Phillips-Perron, ratificando os resultados encontrados na Tabela 3, como pode ser visto no Anexo I. Uma vez que as variáveis consumo privado, consumo público, M4, PIB e poupança externa são integradas de mesma ordem, resta verificar se elas têm um comportamento de longo prazo; em outras palavras, se elas cointegram.

Um dos métodos de cointegração é o de Engle-Granger (o mais usual). Esse procedimento é utilizado quando as variáveis são integradas de mesma ordem e os resíduos da regressão de cointegração (séries em nível) são estacionários. A regressão a ser estimada exclui a taxa de juros, dado que esta é $\mathrm{I}_{\mathrm{o}}$. A equação estimada assume a seguinte forma:

$$
C_{p r i v(t)}=\beta_{0}+\beta_{1} C_{p u b(t)}+\beta_{2} Y_{(t)}++\beta_{3} M 4_{(t)}+\beta_{4} P E_{(t)}+\varepsilon_{(t)}
$$

Como a variável $\mathrm{M} 4$, mesmo em nível, teve uma estatística $t$ insignificante, ela foi retirada do modelo e uma nova estimação para os parâmetros foi feita. Os resultados estão no Quadro 1.

Quadro 1 - Resultados regressão da equação (2)
$C_{\text {priv }}=-35020+0,93 Y-1,65 C_{\text {pub }}+0,6 P E$
sd
21042
0,09
0,45
0,5
$R^{2}=0,93 \quad F(3,22)=92,859 \quad D W=1,37$

Como era de se esperar, o $R^{2}$ encontrado apresenta-se elevado $(0,926807)$, as estatísticas $\mathrm{F}$ e $\mathrm{t}$ também apresentam valores altos e o valor 
do teste Durbin-Watson indica correlação dos resíduos. $O$ interessante de se notar é que, caso as séries cointegrem, o resultado, expresso na Tabela 3 indica que um aumento no consumo do governo implica uma redução de 1,6 no consumo privado, ou seja, um aumento da poupança privada. Entretanto o coeficiente encontrado é maior que 1, indicando que, mesmo que as séries cointegrem, o resultado de CSH não é válido.

Porém, antes de se testar a cointegração, é necessário proceder mais um teste, o da estacionariedade dos resíduos. Os resultados indicam que os mesmos são estacionários, conforme o apresentado na Tabela 4 e nos anexo $\mathrm{V}$.

Tabela 4 - Teste de Estacionariedade dos Resíduos

\begin{tabular}{c|c|c}
\hline Variável & t-adf & t crítico $1 \%$ \\
\hline Resíduos & $-2,935^{* *}$ & $-2,67$ \\
\hline
\end{tabular}

Podemos concluir que, apesar da regressão ser entre variáveis integradas de mesma ordem e os resíduos serem estacionários, a regressão não passa no teste de cointegração ${ }^{7}$. O valor crítico a $5 \%$ para uma regressão com três regressores $l_{1}$ e vinte e cinco observações é de 5,49 (Harris, 1995) ${ }^{8}$.

Fica mais uma vez caracterizado que, para o caso brasileiro, as conclusões de CSH não são válidas. Entretanto, desta vez, a amostra analisada foi expandida (mesmo assim ainda é considerada pequena quando se pretende fazer um estudo mais profundo em séries de tempo) e a cointegração foi testada, usando um maior número de variáveis (uma vez que se tenta aproximar do processo gerador de dados é importante não excluir nenhuma variável).

Outro teste de cointegração realizado foi o de Johansen, apenas corroborando o teste de Engle-Granger. A vantagem do primeiro teste é que ele não postula a relação de causalidade entre as variáveis. No teste de Engle-Granger, a cointegração testada é do consumo público influenciando o consumo privado; mas como as variáveis são datadas no mesmo período (contemporaneidade), seria necessário um teste de exogenidade para garantir que, realmente, a relação se dá nește sentido e não no sentido contrário ou nos dois sentidos. No teste de cointegração de Johansen (que

\footnotetext{
${ }^{7}$ No caso do teste de cointegração, considerando apenas consumo privado e público, cabe destacar que os residuos são não estacionários, sendo, portanto, desnecessário realizar o teste.

${ }^{8}$ Para verificar se as séries cointegram, consoante a metodologia Engle-Grange, não é suficiente apenas verificar se as variáveis são intergadas de mesma ordem e os resíduos estacionários. É necessário submeter os resíduos ao teste de cointegração - uma tabela com os valores críticos.
} 
serve como um indicador de exogeneidade fraco) são testados pelo menos dois vetores de cointegração. No caso estudado, foram testados quatro vetores de cointegração: (i) consumo privado, (ii) PIB, (iii) consumo público e (iv) poupança externa. O Quadro 2 traz os resultados do teste de cointegração para cada um dos vetores.

Quadro 2 - Resultados de Cointegração de Johansen

\begin{tabular}{rll} 
Cointegration analysis 1969 to & 1995 \\
eigenvalue æi & \multicolumn{3}{l}{ loglik for rank } \\
& -1512.35 & 0 \\
0.660656 & -1497.76 & 1 \\
0.555968 & -1486.80 & 2 \\
0.125235 & -1484.99 & 3 \\
0.0155429 & -1484.78 & 4
\end{tabular}

$\begin{array}{lrrrrrr}\text { Ho:rank=p - } & \text { Tlog(1-æ) } & \text { using T-nm } & 95 \%-\text { Tälg(1-æ) } & \text { using T-nm } & 95 \% \\ p==0 & 29.18^{\star} & 24.86 & 27.1 & 55.14^{\star \star} & 46.97 & 47.2 \\ p<=1 & 21.92^{\star} & 18.67 & 21.0 & 25.96 & 22.11 & 29.7 \\ p<=2 & 3.613 & 3.077 & 14.1 & 4.036 & 3.438 & 15.4 \\ p<=3 & 0.423 & 0.3603 & 3.8 & 0.423 & 0.3603 & 3.8\end{array}$

standardized á' eigenvectors

$\begin{array}{cccr}\text { Cons_priv } & \text { PIB_milhöes } & \text { Cons_Pub } & \text { Poup_Ext } \\ 1.000 & -0.002417 & -3.043 & 0.007450 \\ 611.8 & 1.000 & 560.7 & -1.640 \\ -0.6277 & -0.00002620 & 1.000 & 0.00008489 \\ -719.2 & -0.3304 & 6881 & 1.000\end{array}$

standardized à coefficients

$\begin{array}{lrrrr}\text { Cons_priv } & -0.04389 & 6.881 \mathrm{e}-006 & 0.1871 & 0.00001088 \\ \text { PIB_milhões } & -540.3 & -2.367 & -69.90 & -0.02248 \\ \text { Cons_Pub } & -0.004001 & -1.989 \mathrm{e}-007 & -0.03750 & 1.674 \mathrm{e}-006 \\ \text { Poup_Ext } & -326.7 & -0.7685 & 0.9315 & -0.01614\end{array}$

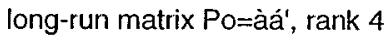

\begin{tabular}{|c|c|c|c|c|c|c|}
\hline & Cons_priv & PIB_milhões & Cons_Pub & Poup_Ext & & \\
\hline Cons_priv & -0.1649 & 0.0001045 & 0.3993 & -0.0003115 & & \\
\hline PlB_milhões & -1928. & -1.051 & 92.64 & -0.1722 & 3 & \\
\hline Cons_Pub & 0.01821 & $9.902 e-006$ & -0.01392 & -0.00003100 & 3 & \\
\hline Poup_Ext & -785.8 & 0.02644 & 453.1 & -1.190 & & \\
\hline
\end{tabular}

Os resultados acima indicam que pode haver cointegração para o vetor $1(p=0)$ e que não há cointegração para os demais. $O$ vetor 1 refere-se ao primeiro VAR, onde o consumo privado é estimado como função dele mesmo, defasado e das demais variáveis defasadas. Neste ponto aparece uma das falhas deste método de cointegração, pois é necessário testar se esta cointegração é estável. Para tanto, é necessário montar um outro sistema com as variáveis com uma defasagens de dois lags e submetê-lo à 
cointegração. Os resultados encontrados indicam a não cointegração. $O$ mesmo procedimento foi aplicado para o caso de 3 e 4 lags, também indicando resultados negativos. Assim, pode-se concluir que, para a amostra estudada, não se pode estabelecer uma relação de longo prazo entre a poupança privada e a pública. Portanto os resultados de $\mathrm{CSH}$, em relação à poupança governamental e à nacional, devem ser tomados com bastante cuidado para o caso brasileiro.

\section{5 - CONCLUSÃO}

Este trabalho apresentou uma análise na mesma linha dos estudos de Bastos e Gomes (1996) e Bastos e Teixeira (1997), criticando as conclusões de Corbo e Schmidt-Hebbel (1991) para o Brasil. Contudo foi aqui utilizada uma série ampliada dos dados estatísticos. Além disso, não só usou-se um maior número de variáveis para testar a cointegração, como também técnicas econométricas mais avançadas. Com base nos resultados obtidos, mostrou-se que não se pode tirar conclusões a respeito da interação entre poupança governamental e privada para cada país da amostra, quando tomados individualmente.

Outro fato a ser destacado diz respeito à abordagem metodológica e à credibilidade das previsões econômicas. A utilização da econometria clássica (ou a falta de rigor econométrico) como corroboradora de uma posição ortodoxa preconcebida mostrou-se falaciosa. E, se seguida, geraria resultados práticos diferentes das previsões do modelo; ajudando a diminuir a credibilidade das previsões feitas por economistas - já tão em baixa.

Não há validade empírica, no caso brasileiro, para a defesa da redução dos gastos públicos como condição necessária para o crescimento econômico. Ou, mesmo, de que é suficiente reduzir os gastos públicos para aumentar a poupança nacional e, assim, reduzir a dependência do capital internacional (gerador de instabilidades). Nada garante que uma redução dos gastos públicos vá gerar um aumento da poupança nacional no longo prazo (falta de cointegração entre poupança governamental e privada).

Seguindo o paper de Bastos e Teixeira (1997), cabe lembrar que os resultados obtidos não descartam a possibilidade de que os déficits do governo sejam um fator relevante para a determinação do nível de poupança nacional, mas sim mostram o perigo de estudar certas variáveis macroeconômicas sem o devido cuidado metodológico. Apesar do período amostral ter sido aumentado, a amostra ainda é pequena. Recomenda-se que, para futuras pesquisas, a amostra seja aumentada, através da utilização de dados mensais ou trimestrais e que se leve em consideração o efeito dos fundos privados de pensão sobre a poupança doméstica. 


\section{BIBLIOGRAFIA}

BASTOS, Fabiano Rodrigues e GOMES, Michel R. Amariz. Relação entre poupanças governamental e nacional: uma contribuição crítica, Brasília: UnB, 1996, mimeo.

CORBO, Vittorio e SCHMIDT-HEBEL, Klaus. Public policies and saving in developing countries. Journal os Development Economics, 36, p. 89-115, 1991.

FUNDAÇÃO GETÚlIO VARGAS. Revista Conjuntura Econômica, Rio de Janeiro: vários números.

GRANGER, C. W. J. \& NEWBOOLD, P. Spurious Regressions in Econometrics. Journal of Econometrics, 2, p. 111-120, 1974.

GREENE, William H. Econometric Analysis. United States: Ed. Prentice Hall, ed. 3a 1997. GUJARATI, Damodar N. Basic Econometrics, Singapore: Ed McGraw-Hill, ed. 3 ${ }^{\text {a }} 1995$.

HARRIS, Richard I. D. Using Cointegration Analysis in Econometric Modelling, Great Britain: ED. Prentice Hall, 1995.

IMF, International Financial Statistics, Yearbook 1996 and July 1997. Washington.

JUDGE, George G.; HILL, R. Carter.; GRIFFITHS, William E.; LUTTKEPOHL, Helmut.; LEE, Tsoung-Chao. Introduction to the Theory and Practice of Econometrics, United States: ED.Wiley, ed. $2^{\mathrm{a}}$, 1988.

TEIXEIRA, Joanílio R. e BASTOS, Fabiano Rodrigues. Relação entre poupança governamental e nacional (1980-1995): uma contribuição crítica. Anais do $2^{\circ}$ Encontro Brasileiro de Economia Política, São Paulo, maio, 1997. 


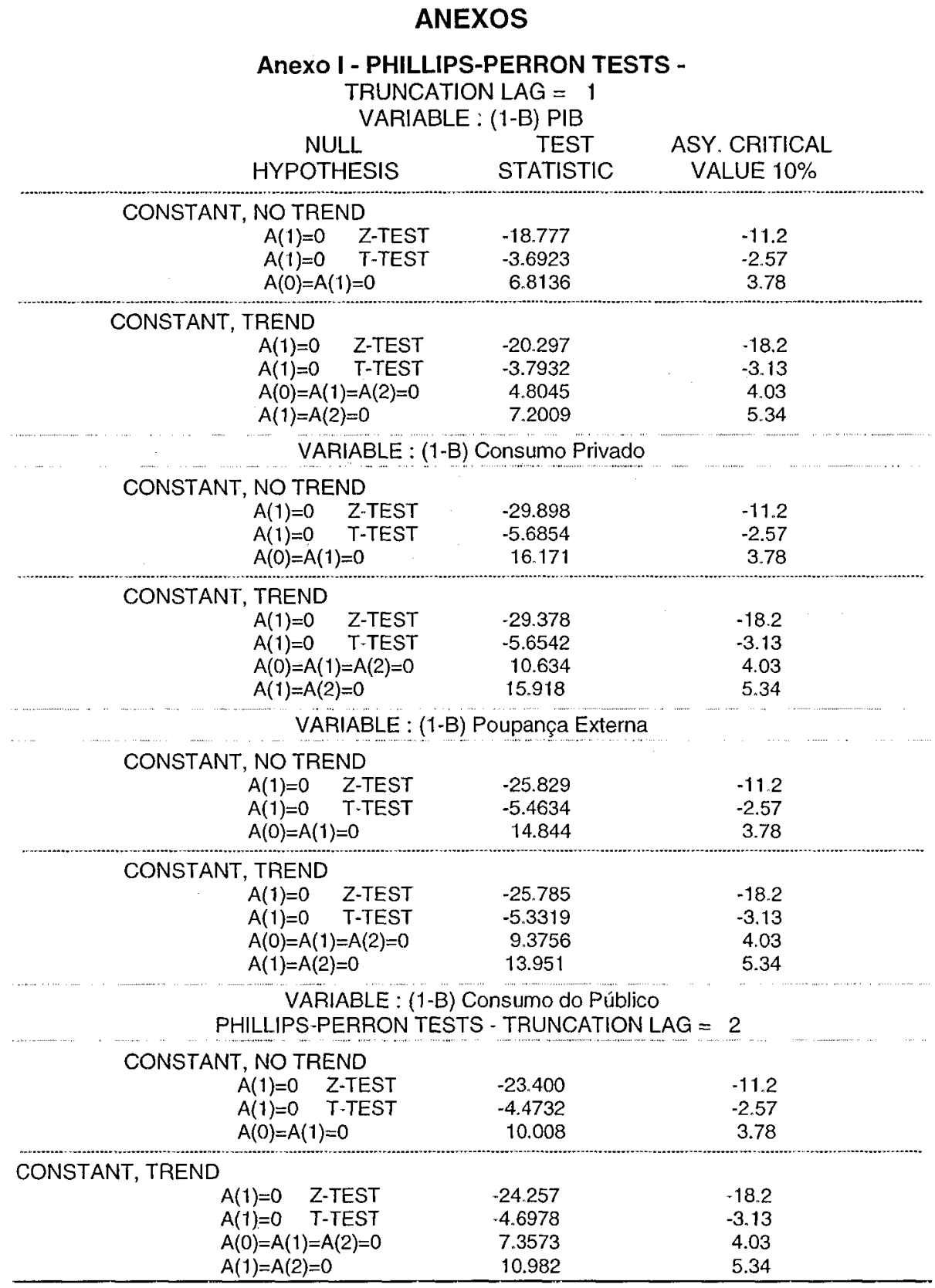

